\title{
IDEÁRIO PEDAGÓGICO MUNICIPALISTA DE ANÍSIO TEIXEIRA
}

\author{
HELOISA OCCHIUZE DOS SANTOS \\ Doutora pela Faculdade de Educação da USP - FEUSP \\ Professora e Pesquisadora da Universidade Bandeirante de São Paulo - \\ UNIBAM
}

\section{RESUMO}

Em sintonia com os princípios democráticos inspirados pela filosofia educacional de John Dewey, Anísio Teixeira foi construindo ao longo das suas atividades na vida pública, o que neste artigo se chamou de ideário pedagógico municipalista. O artigo apresenta essa trajetória pública: Bahia (1924 - 1929); Distrito Federal (1931 1935); Bahia (1947 - 195 I); Rio de Janeiro (1952 - 1961); Rio de Janeiro (1962 - 1968); Brasilia (1963 1964); Rio de Janeiro (1967- 1970).

MUNICIPALIZAÇÃO DEENSINO-DESCENTRALIZAÇÃO DAEDUCAÇÃO- QUALIDADEDEENSINO-TEIXEIRA, ANISIO

\section{ABSTRACT}

ANISIO TEIXEIRA'S "MUNICIPALIST" PEDAGOGICAL REPERTORY. In harmony with the democratic principles inspired by the educational philosophy of John Dewey, Anisio Teixeira, during the years of his public life constructed what this article calls a "municipalist" pedagogical repertory of ideas. The article present this public trajectory: Bahia (1924 - 1929); Distrito Federal (1931 - 1935); Bahia (1947 - 1951); Rio de Janeiro(1952 - 1961); Rio de Janeiro (1962 - 1968); Brasilia (1963 - 1964); Rio de Janeiro(1967-1970).

Este artigo foi organizado com base no primeiro capítulo de tese de doutorado defendida na Faculdade de Educação da USP (Santos, 2000), sob orientação do professor doutor José Mario Pires Azanha. 


\section{APRESENTAÇÃO}

A matriz do pensamento democrático de Anísio Teixeira está em John Dewey, de quem fora aluno, discípulo e tradutor, tornando-o, dessa maneira, conhecido no Brasil.

Dewey era um filósofo que defendia a educação pública como um ideal de democracia. Para ele, só a educação torna possível a vida em comunhão, "em que os interesses se interpenetram mutuamente", diminuindo os efeitos das desigualdades econômicas e proporcionando a todos os cidadãos a igualdade no desenvolvimento profissional. Do contrário, esse ideal democrático não passará de "uma ilusão tão ridícula quanto trágica" (Dewey, 1952, p. 140).

Seguindo esses princípios democráticos, Anísio Teixeira foi elaborando, ao longo das suas atividades na vida pública, o que aqui se vai chamar de ideário pedagógico municipalista.

\section{BAHIA: O JOVEM EDUCADOR (1924 - 1929)}

Em 9 de abril de 1924, com 24 anos, o jovem Anísio Teixeira, bacharel pela Faculdade de Direito do Rio de Janeiro, foi nomeado Inspetor Geral do Ensino da Bahia, defendendo o ensino público laico - princípio, aliás, já consagrado na Constituição de |89| - e gratuito e notabilizando-se pela idéia, na época inovadora, do "localismo educacional", expressão usada por Abreu (1960), correspondente ao que hoje chamamos de municipalização do ensino.

Logo no segundo ano da sua gestão, criou a Lei n. 1.846, de 14 de agosto de 1925, para reformar a Instrução Pública do Estado da Bahia, secundada pelo Decreto n. 4.312/ 25, para aprovar o Regulamento do Ensino Primário e Normal.

Com essa lei, propunha-se a criação daquilo que seriam os primeiros Conselhos Municipais de Educação no país, para: estimular o desenvolvimento do ensino primário, fiscalizar o serviço escolar do município e propor medidas convenientes à melhor adaptação do ensino às condições locais.

A previsão dos Conselhos Municipais de Educação mostra como é firme e antiga no pensamento de Anísio Teixeira a idéia de não fazer do aparelho escolar uma instituição puramente proconsular, superimposta pelo Estado aos municípios, sem participação dos municípios nesse serviço... (Abreu, 1960, p. 4)

No entanto, só em 1964, quase 40 anos depois, é que foi autorizado pelo já criado Conselho Federal de Educação, aquele que foi considerado o primeiro Conselho 
Municipal de Educação, não na Bahia, mas na cidade de Estrela no Rio Grande do Sul (Brasil, 1964).

Na mesma lei de 1925 foi definida uma política educacional de governo, em relação à administração do ensino primário, que previa uma forma descentralizada de parceria entre estado e município:

Artigo 70 - O ensino primário, a cargo dos municípios, constituirá com o do estado, um só e mesmo serviço, sob a direção geral, superintendência e fiscalização do Governo do Estado.

Artigo 7 I - É reconhecida aos municípios a competência para criar, manter, transferir e suprimir escolas de instrução primária, dentro de sua circunscrição territorial, subentendido, porém, o exercício dessa competência nos limites da presente lei e de acordo com as suas normas e preceitos. (Abreu, 1960, p. I5)

Tratou também do financiamento da educação:

Artigo 72 - ...a quota da receita municipal atribuída a instrução primária não poderá ser inferior à sexta parte da renda ou receita geral do município [...].

Artigo 73 - ... a instrução primária municipal relativa aos vencimentos do professorado e locação escolar passará a ser paga no Tesouro do Estado, mediante atestados do exercício do magistério... (Idem, ibidem)

No meio cultural e educacional recebeu críticas veiculadas pelos jornais que o caricaturavam como: "o verdoso educador", o "bebê", o "irrequieto pedagogo". E entre os titulares do poder político e no meio legislativo, suas posições foram combatidas: a do localismo educacional, por causa das incursões do clientelismo eleitoral, e a da laicidade do ensino, embora preceito constitucional, considerada uma "inovação do moço educador". Essas eram críticas previsíveis, pois segundo Abreu:

Homem que sempre marchou na vanguarda do seu tempo, era natural que entre o molde cultural baiano, predominantemente conservador, estático, e a configuração mental dinâmica de Anísio, uma arritmia essencial se estabelecesse. (1960, p. 37)

Em abril de 1927, foi à América do Norte, onde realizou, comissionado por lei, "estudos de organização escolar". No ano seguinte, voltou por mais dez meses para realizar o seu Master of Arts no Teachers College da Columbia University. Ao regressar, Anísio Teixeira elaborou suas Sugestões para reorganização progressiva do Sistema Educacional Baiano. Nenhuma delas, contudo, foi implantada por falta de autonomia de execução e, por isso, em 1929, pediu exoneração do cargo de Inspetor Geral do Ensino da Bahia.

Antes de deixar o cargo apresentou ao governador' de estado da Bahia o estudo

I. Que pela constituição vigente era considerado presidente de estado 
O ensino no Estado da Bahia 1924 - 1928, inspirado nas idéias de Dewey e no sistema escolar americano.

Considerando que os problemas educacionais transpunham os limites do próprio estado, denunciou a falta de uma educação popular, a existência de um sistema político autoritário e excludente, e a intervenção centralizadora da União nos serviços do ensino.

Os acordos para o ensino primário, e agora, os acordos para o ensino profissional com que a União tem procurado colaborar com o estado, nos serviços de ensino, se propõem em bases inaceitáveis ou pelo menos discutíveis pelo estado, porque a União deseja fazer da subvenção uma intervenção. (Abreu, 1960, p. 28)

Insistiu no fato de que o nível prioritário da escala escolar deveria ser o ensino primário, a base da pirâmide do serviço de educação para onde deveriam convergir os esforços centrais do governo. A escola primária deveria ter um currículo básico integrado à comunidade local e com reflexos na própria escola:

...buscando exercitar nos meninos os hábitos de observação e raciocínio, despertando-lhes o interesse pelos ideais e conquistas da humanidade, ministrando-lhes noções rudimentares de literatura pátria, fazendo-os manejar a língua portuguesa como instrumento de pensamento e expressão; guiando-Ihes as atividades naturais dos olhos e das mãos mediante formas adequadas de trabalhos práticos e manuais; cuidando, finalmente, do seu desenvolvimento físico, com exercícios e jogos organizados e conhecimento das regras elementares de higiene, procurando sempre não esquecer a terra e o meio que a escola deseja servir, utilizando-se o professor de todos os recursos para adaptar o ensino às particularidades da região e do ambiente baiano. (Idem, p. 22)

Sobre avaliação, repetência e evasão escolar, propôs pioneiramente critérios de promoção flexível:

O número tremendo de alunos que repetem os anos no curso primário, representa alunos com os quais o estado está despendendo o dobro, o triplo e o quádruplo do que devia gastar, se a organização escolar baiana fosse adequada em todo o sentido.

Os técnicos americanos são hoje acordes em que não deve haver repetições de ano em um sistema escolar.

Se o curriculum for devidamente organizado, de sorte a progredir, através dos graus, à medida que a criança progredir, através dos anos e, por outro lado, houver um sistema objetivo e científico de medir o progresso do escolar, não deve haver reprovações no sistema escolar. (Idem, p. 25, grifos do original)

Critério semelhante foi instituído quase 70 anos depois, na atual Lei de Diretrizes e Bases - LDB -, n. 9.394, de 20 de dezembro de 1996: "os estabelecimentos que utilizam progressão regular por série podem adotar no ensino fundamental o regime de progressão 
continuada, sem prejuízo da avaliação do processo de ensino-aprendizagem, observadas as normas do respectivo sistema de ensino" (Artigo 32).

Em 1930, por pouco menos de um ano, foi o primeiro Diretor do Ensino Secundário no recém-criado Ministério da Educação e Saúde Pública, sendo ministro Francisco Campos.

\section{DISTRITO FEDERAL: O HOMEM DE AÇÃO (|93। - 1935)}

Em I 5 de outubro de 1931, Anísio Teixeira passou a ocupar o cargo de Diretor do Departamento de Educação da Capital da República. Pode-se dizer que, naquele mês e ano ia iniciar-se no Rio de Janeiro, sem qualquer exagero, como afirma Lemme (1988, p. 121), "a mais criativa, corajosa e também controvertida administração de ensino como jamais se verificara no país". Para o autor, que foi seu secretário desde 1932, isso se deu não somente em razão das qualidades pessoais, de temperamento e de formação cultural e técnica do novo diretor, mas também pelo conturbado momento histórico vivido pelo país.

Depois da Revolução de 30, reinava um clima de euforia e uma crescente consciência dos problemas educacionais brasileiros, como se percebe no pronunciamento de Getúlio Vargas, chefe do Governo Provisório, durante a sessão inaugural da IV Conferência Nacional de Educação, em 13 de dezembro de 1931:

Quero trazer-vos, com a minha presença e com a minha palavra, a afirmação de que o governo, mais do que nunca, se há de interessar pelo problema da educação nacional. Estais agora aqui congregados, sois todos profissionais e técnicos. Pois bem: estudai com dedicação; analisai com interesse todos os problemas da educação; procurai encontrar a fórmula mais feliz de colaboração do Governo Federal com o dos estados - que tereis na atual administração todo o amparo ao vosso esforço. (Vargas, 193।, p. 5)

Os educadores que aspiravam a reconstruir a educação no país, entre os quais estavam Anísio Teixeira, Sampaio Dória, Lourenço Filho, Hermes Lima e Paschoal Leme, opunham-se aos pensadores católicos - que defendiam o ensino religioso e a escola privada - e envolveram-se na luta pela democratização do ensino, elaborando então o Manifesto dos Pioneiros da Educação Nova, redigido por Fernando de Azevedo e publicado em 1932. A repercussão do "Manifesto" foi tamanha que assim falou Azevedo Amaral:

\footnotetext{
O mal-estar que oprime o país e se traduz em nostalgia de uma forma qualquer de organização política sistematizada e expressa na definição de princípios constitucionais decorre da esterilidade intelectual do após-revolução, despontando a expectativa pública de diretrizes novas, que, mesmo quando fossem violentamente audaciosas, seriam muito mais aceitáveis e menos perigosas que a estagnação de um país revolucionado, isto é, a posição insustentável de uma Nação que rompe com o passado e fica perplexa entre ruínas e um futuro para o qual não se atreve a caminhar. (Viana Filho, 1990, p. 58)
} 
Considerado a "espinha dorsal ideológica do 'Manifesto'”, Anísio Teixeira já almejava, como ele mesmo declarou mais tarde ao Diário de Notícias da Bahia, "elevar a educação à categoria do maior problema político brasileiro, dar-lhe base técnica e científica, fazêla encarnar os ideais da república e da democracia" (Tavares, 1952, p. 10).

Como administrador da educação da capital da República, pretendia contribuir para a reorganização do sistema de educação pública do país. Localmente, deu continuidade à orientação de Fernando de Azevedo, empreendendo mudanças na organização e no funcionamento do Departamento de Educação.

Tornou o ponto alto da sua administração a organização do aparelho de direção, orientação e fiscalização do sistema educacional, visando a um melhor rendimento escolar, numa ação reflexa do seu compromisso com a qualidade de ensino das escolas públicas.

A preocupação com o melhor rendimento escolar resultou numa rigorosa unidade de linhas de ação entre os setores administrativos e técnicos, de maneira que se criasse, entre o professor e a administração central, uma relação dinâmica que promovesse uma "comunidade de objetivos, identidade de problemas e circulação de conhecimentos, experiências e resultados", mas com autonomia para desenvolver a tarefa educativa (Teixeira, 1936, p.161).

No plano nacional, foi presidente e relator, em 1933, da "Comissão dos Dez" - de que participaram também Arthur Moses, Afrânio Peixoto, Frota Pessoa, Fernando de Azevedo, Isaías Alves, José Augusto, Lourenço Filho, Lisymaco da Costa e Sampaio Dória -, constituída pela Associação Brasileira de Educação - ABE. Essa comissão, tendo por base o Manifesto dos Pioneiros da Educação Nova, elaborou sugestões para o capítulo da educação da nova Constituição Brasileira, bem como para o Plano Geral da Educação Nacional. Muitas dessas sugestões foram incorporadas ao texto constitucional, e é o próprio Anísio quem faz um resumo das medidas aceitas pelo Congresso:

I. A educação pública não se organiza por meio de regulamentos únicos e exclusivos da União ou dos estados, cada um regendo soberanamente os seus setores.

2. Uma ampla lei orgânica nacional deve, pois, fixar, nas suas grandes finalidades, na sua graduação e nas suas ramificações, o sistema nacional de educação, contínuo, articulado e flexível para que não coarcte as iniciativas locais, nem desobedeça às suas condições peculiares.

3. Se assim reconheceu o Congresso, cabe à União, pela primeira vez, legislar sobre os objetivos e a articulação de todas as escolas públicas brasileiras, acabando-se por completo com os sistemas estanques anteriores - federal e estaduais - , também reconheceu o mesmo Congresso que aos estados e ao Distrito Federal, caberá, então, organizar, custear e administrar as suas escolas dentro do plano nacional de educação.

4. Corrigia-se, assim, o erro da falta de unidade dos sistemas escolares brasileiros, vinte e um estaduais e mais um federal, e confiava-se à autoridade estadual a competência de organização, custeio e administração do sistema escolar que the fosse possível manter, dentro do plano nacional.

5. Não se fechava, entretanto, a porta ao Governo Federal, caso se quisesse corrigir de quaren- 
ta anos de incúria; dava-se-lhe a função de coordenar e estimular a obra educacional de todo o país, manter estabelecimentos de demonstração e experiência e ainda a de exercer uma ação supletiva onde se fizesse mister, por deficiência de meios ou iniciativas.

6. A sabedoria do plano proposto pelo Congresso estava em que se corrigia um erro fundamental da organização do ensino público brasileiro e, ao mesmo tempo, não se impedia nenhum desenvolvimento já existente, nem outros que viessem a surgir. Pareceu-nos, sempre, ser esse um dos segredos de disposição constitucional sobre a educação. (Teixeira, 1936, p. 284)

Na Constituição de 1934, ficaram consagrados os seguintes princípios democráticos: a obrigatoriedade e a gratuidade do ensino primário; o direito de todos à educação; a obrigatoriedade do ensino gratuito; a instituição da unidade, descentralização e autonomia dos serviços de ensino público. Confirmaram-se também: a criação de um Conselho Nacional de Educação para fixar um Plano Nacional de Educação e a determinação das porcentagens mínimas que deveriam ser aplicadas pela União, estados, Distrito Federal e municípios para manutenção e desenvolvimento do ensino. Esse resultado representou para os "Pioneiros" e para Anísio Teixeira, em particular, elevar a educação à condição de elemento fundamental da vida democrática, condição essa que ele já vinha defendendo desde que assumiu o seu primeiro cargo público na Bahia, há dez anos.

Em 2 de setembro de 1935, pela Lei n. 7, foram reorganizados os serviços da Prefeitura e do Distrito Federal, sendo o Departamento da Educação transformado em Secretaria Geral de Educação e Cultura (Lemme, 1988, p. 162). A criação da Secretaria Geral de Educação e Cultura permitiu a Anísio Teixeira ampliar o âmbito de ação dos serviços de educação, por intermédio de dois setores principais: um encarregado do ensino sistemático ou comum, e outro, responsável por toda a educação assistemática, ou seja, educação de adultos e difusão cultural.

Durante a sua gestão, dedicou especial atenção e estudos ao ensino primário, que apresentava altos índices de reprovação e evasão. Segundo Silveira (1960, p. 198), "pela primeira vez se pode constatar por dados estatísticos fidedignos, a gravidade do problema da repetência, quer do ponto de vista econômico, quer sobretudo, do ponto de vista humano e social".

O inquérito que realizou em 1932 revelou que dos 79 prédios municipais, apenas 12 estavam em condições satisfatórias, os demais precisariam passar por reformas e outros até ser fechados por falta de condições mínimas de funcionamento. Cioso de que esse problema não poderia ser resolvido por uma só administração, organizou, pela primeira vez, um programa de construções para um decênio, desdobrado em duas etapas qüinqüenais, prevendo a localização da escola de acordo com as tendências de crescimento da população. Até o final de sua administração foram construídos 35 novos prédios, além das adaptações e reformas, e até 1938, segundo Silveira (1960, p.200), foram construídos os demais prédios necessários à população escolar.

Afrânio Peixoto, em um breve balanço, afirma que no campo educacional nenhum 
educador nacional fez, nos últimos quatrocentos anos, o que Anísio Teixeira fizera no Distrito Federal em quatro anos:

...edificou 26 grandes prédios escolares modernos, sociáveis, para educação pública, instituiu neles a escola progressiva, permitindo experiências pedagógicas de êxito comprovado, organizou a administração do ensino em bases de controle e eficiência, aumentou a matrícula e as assiduidades de 80.000 para I20.000, promoveu por meio de cursos o reajustamento do professorado à atualidade educacional; criou e formou um corpo de orientadores pedagógicos acessório ao exercício escolar; instalou o Instituto de Pesquisas Educacionais; reorganizou o ensino técnico e profissional; instituiu o ensino secundário municipal, comparado, em excelência, ao federal e particular; transformou a antiga Escola Normal em Instituto de Educação, onde um curso geral prepara para a especialização didática, mais preocupado com a matéria e os métodos intrínsecos do seu ensino com a massa total de conhecimentos, do que com imaginários métodos de ministrar qualquer conhecimento ... finalmente criou a Universidade do Distrito Federal. (Viana Filho, 1990, p. 73)

Anísio Teixeira, de 1931 a 1935, criou na Capital Federal um verdadeiro sistema de educação integrado às condições locais, que compreendia desde a pré-escola, o jardim de infância até a universidade.

Depois de quatro anos "de trabalhos árduos, ininterruptos, sem descanso e sem tréguas, em meio a controvérsias ácidas e conquistas brilhantes e compensadoras, tinha produzido, sem dúvida, resultados extremamente positivos" e se podia considerar plenamente vitorioso na realização de sua obra e projetar, com segurança, desdobramento e aperfeiçoamento para o futuro (Lemme, 1988, p. 163).

Acusado de esquerdista e de insuflar idéias comunistas, deixou a secretaria em 2 de dezembro de 1935, um dia depois da conversa que teve com o prefeito Pedro Ernesto, ao perceber que a sua permanência constituía embaraço político. Registrou em sua carta de demissão as suas convicções democráticas:

Não sendo político e sim educador, sou, por doutrina, adverso a movimentos de violência, cuja eficácia contesto e sempre contestei. Toda a minha obra, de pensamento e ação, aí está para ser examinada e investigada, exame e investigação que solicito, para que se descubram outras tendências e outra significação, senão as de reconhecer que o progresso entre os homens provém de uma ação inteligente e enérgica, mas pacífica. (...) reivindico, mais uma vez, para essa obra, que é do magistério do Distrito Federal, e não somente minha, o seu caráter absolutamente republicano e constitucional e a sua intransigente imparcialidade democrática e doutrinária. (Lemme, 1988, p. 165)

No plano nacional, as conquistas democráticas conseguidas em 1934 foram praticamente suprimidas na Constituição² de 1937, com o Estado Novo.

2. A Carta de 37, embora reservasse para a União o exercício da atividade normativa, restringia os deveres do estado na manutenção do ensino e eliminava muitas das conquistas do movimento renovador, tais como: 
Ferozmente perseguido pela reação que se desencadeava violenta por todo o país com o golpe de Estado que instituiu o Estado Novo, Anísio Teixeira precisou se exilar com sua família no interior da Bahia por dez anos.

Em 1946, com a derrubada de Getúlio Vargas no ano anterior, a nova Constituição instituída retoma "a orientação descentralista e liberal da Carta de 1934, restabelecendo grande parte de seus dispositivos sobre a educação" (Haidar, Tanuri, 1998, p. 90).

\section{OUTRA VEZ NA BAHIA: O ADMINISTRADOR (I947 - 195I)}

Com a reconquista dos princípios democráticos, na Constituição de 1946, Anísio Teixeira voltou para o seu segundo mandato na Bahia, agora como secretário de educação e saúde. Em outubro de 1947, no Anteprojeto de Lei Orgânica de Educação e Cultura do Estado, reafirmou sua crença na educação escolar como um ideal de democracia:

...todo o anteprojeto é uma afirmação da confiança que o Estado, em pleno renascimento democrático, deposita na instituição que, por excelência, arma o povo para a conquista da igualdade entre os homens, a escola. [...] Longe vai, com efeito, a fase do desenvolvimento democrático em que se supunha que a escola devia ser neutra e apolítica. Desafiados pela própria evolução das instituições democráticas, precisamos fortalecer aqui e podar e restringir ali, pois aprendemos - e a que preço! - que a democracia não se realiza por si mesma, mas é um produto da vontade organizada e de um propósito lúcido para a conquista dos seus objetivos. [...] Dentre as instituições a fortalecer em sua luta pela eficácia está, mais que qualquer outra, a escola. (Abreu, 1960, p.46)

No primeiro relatório dirigido ao governador, em 1947, denunciou a baixa qualidade do ensino público na Bahia e chamou de "um processo de faz-de-conta" o vício de apontar a falta de escolas como o principal problema da educação. Lembrou também que o projeto da LDB deveria ser, por força da Constituição Federal, uma lei descentralizadora que não poderia "fixar mais do que os padrões externos da educação, ficando todo seu conteúdo para o desenvolvimento local, de acordo com os recursos humanos e materiais do estado" (Abreu, 1960, p.46).

Assim como já tinha feito na sua primeira gestão com relação aos Conselhos Municipais de Educação, fez incluir na Constituição do Estado da Bahia, de 1947, a criação do Conselho Estadual de Educação e Cultura, um "órgão autônomo, financeira e administrativamente". Com isso, o controle e a administração da escola pública passaram da ação

excluiu o princípio de que a "educação é direito de todos" substituindo-o por "um dever e direito natural dos pais", conferindo ao Estado a imprecisa atribuição de não ser "estranho a esse dever, colaborando, de maneira principal ou subsidiária para facilitar sua execução ou suprir as deficiências e lacunas da educação particular" (Haidar, Tanuri, 1998, p. 90) 
direta do estado para uma ação colegiada com representação social: a sociedade e a opinião pública seriam as grandes forças para definir os rumos da educação.

Fiel ao princípio da descentralização com autonomia, propôs a instituição do Fundo de Educação com recursos provenientes das dotações orçamentárias do estado e dos municípios. Os Conselhos Municipais de Ensino, sob a supervisão do Conselho Estadual de Educação, teriam à sua disposição os recursos necessários, retirados do Fundo de Educação, para a função de educação e ensino.

Em 1950, contudo, ainda não havia sido aprovada a Lei Orgânica do estado, que garantiria a eficácia da descentralização administrativa, "a fim de se dar ao ensino primário e ao seu professor condições de trabalho ordenado, estímulo e progresso" (Abreu, 1960, p. 64).

Anísio Teixeira encerrou a sua segunda gestão sem conseguir alterar o grave quadro educacional no estado baiano, mas manteve a crença nos ideais democráticos:

Não fizemos muito. Mas que prazer e que alegria trabalhar, como trabalhamos, em um governo notável pelo que fez de palpável e concreto mas sobretudo excepcional pelo que realizou de invisível: a justiça, a liberdade e a confiança. (Tavares, 1952, p. 13)

Na gestão seguinte, seu Anteprojeto de Lei Orgânica para Educação e Cultura foi transformado numa pura e simples lei de cargos, vencimentos e vantagens.

\section{OUTRA VEZ NO DISTRITO FEDERAL: O INTELECTUAL (|952 - |96|)}

Como Diretor do Instituto Nacional de Estudos Pedagógicos, Anísio Teixeira, pela segunda vez em um cargo de projeção nacional na Capital da República, teve uma fase de grande produção intelectual, publicando mais de 20 trabalhos na Revista Brasileira de Estudos Pedagógicos que reafirmavam sua filosofia de educação, num momento em que ainda se discutia a aprovação do projeto da LDB.

Em "A crise educacional brasileira", propôs dez medidas prioritárias para melhorar a educação pública, dentre as quais se destaca o princípio da descentralização. É nesse texto que falou pela primeira vez em "municipalização":

Primeiro, descentralizar administrativamente o ensino, para que a tarefa se torne possível, com a distribuição das responsabilidades pela execução das medidas mais recomendáveis e recomendadas.

\section{$[\ldots]$}

...julgamos que é chegada a ocasião de "municipalizar" a escola pública, entregando-a ao município, que a manterá com os recursos do Fundo Escolar Municipal.

No começo a escola não seria melhor que a atual. Mas, à medida que se fossem desenvolvendo as virtualidades do sistema e fossem sendo percebidas as possibilidades do regime de responsa- 
bilidade assim criado [estados e municípios], forças insuspeitadas de iniciativa e de emulação surgiriam para conduzir o conjunto do sistema nacional ou os múltiplos sistemas escolares solidários, ao mais alto nível de decência e eficiência. (Teixeira, 1953, p. 36-41 , grifos do original)

O ensino primário deveria ficar sob responsabilidade legal dos municípios, permitindo uma descentralização com autonomia nunca antes experienciada no país; e contribuindo também para que os usuários das escolas públicas se envolvessem no processo para atingir a meta qualitativa da educação.

Criemos as condições necessárias a uma ampla experimentação social, mediante uma legislação [a LDB] proposta antes a dar os poderes e faculdade de organização do que a "organizar" a educação escolar, a educação nacional, como cousa pré-fabricada e imposta. (Teixeira, 1953, p. 42)

Na sua filosofia, uma escola integrada numa comunidade local, municipalizada, que atendesse a todos sem discriminação, colocaria em prática o ideal democrático de igualdade de oportunidades e proporcionaria, de fato, a participação da comunidade em defesa da escola pública.

Em 1954, apresentou no X Congresso Brasileiro de Educação, em Curitiba, o trabalho "Sobre o problema de como financiar a educação do povo brasileiro", propondo medidas para administrar o Fundo de Educação previsto na Constituição de 1946, entre elas, as competências e a articulação do Conselho Estadual de Educação com o Conselho Escolar local.

No seu artigo "O processo democrático de educação", reiterou a defesa da educação popular e da escola democrática que põem em prática o ideal democrático de participação de todos como uma "atitude fundamental do professor, do aluno e da administração" (Teixeira, 1956, p. 7).

Em setembro de 1956, retomou as idéias em defesa de educação pública, universal e gratuita, na conferência de abertura do I Congresso Estadual de Educação, na cidade de Ribeirão Preto, interior de São Paulo, e demonstrou a sua posição municipalista.

Numa sociedade como a nossa, tradicionalmente marcada de profundo espírito de classe e de privilégio, somente a escola pública será verdadeiramente democrática e somente ela poderá ter um programa de formação comum, sem os preconceitos contra certas formas de trabalhos essenciais à democracia.

\section{$[\ldots]$}

A nova escola pública, de administração municipal, ou autônoma, não deixaria de ser estadualpelo professor, formado e licenciado pelo estado, embora nomeado pelo órgão local, pela assistência técnica e pelo livro didático e material de ensino, elaborados sem dúvida no âmbito do estado em seu conjunto. E, permitam-me ainda dizer, não deixaria de ser federal- pela obediência à lei nacional de bases e diretrizes e, ainda, talvez, pelo auxílio financeiro e a assistência técnica que os órgãos federais lhe viessem a prestar. 
Pela democratização e autonomia daríamos meios eficazes para a administração mais eficiente das escolas e responsabilidade dignificante a diretores e professores, que não estariam trabaIhando em obediência a ordens distantes, mas sob a inspiração dos seus próprios estudos e competência profissional. (Teixeira, 1977, p. 72, 74 e 76, grifos do original)

Finalmente, em abril de 1957, apresentou sua tese sobre "Municipalização do Ensino Primário" no Congresso Nacional de Municipalidade, baseado na constatação de que as "administrações municipais, tantas vezes julgadas, à ligeira, como as menos capazes das administrações públicas brasileiras" e que "muitos observadores vêm considerando a escola municipal muito mais integrada no meio que a escola estadual, o que constitui elemento positivo a favor daquela instituição" (Teixeira, 1957, p.33).

Buscando índices para comprovar a real qualidade da escola primária municipal, concluiu que havia uma disparidade muito grande entre os recursos destinados à escola municipal e às escolas estaduais e federais: enquanto os municípios arrecadaram 10,59\%, em 1954, e 9, 45\%, em 1955, a União, o Distrito Federal e os estados arrecadaram o que restava: $89,41 \%$ e $91,55 \%$, respectivamente.

Além disso, o custo do aluno da escola estadual era seis vezes superior ao do aluno da escola municipal, sendo que ambas aprovavam menos de 10\% dos alunos matriculados.

Segundo ele, "deve-se reconhecer que as administrações municipais, a despeito de suas tremendas dificuldades de recursos e de pessoal, vêm realizando um esforço que pode sofrer honroso confronto com as administrações federal e estaduais".

Portanto, para ele, a tese de municipalização do ensino era também um incentivo ao esforço local e ao mesmo tempo uma correção para que os municípios pudessem continuar oferecendo ensino com melhores condições, fazendo "ressurgir o regional e o autêntico na cultura brasileira, ameaçados e feridos pelos restos de centralização colonialista de que ainda não nos emancipamos e que tanto se refugiam ainda nas instituições educativas" (Teixeira, 1957, p.37-40).

A municipalização do ensino no contexto do seu ideário pedagógico municipalista faz lembrar as idéias de Brooke ( 1989 ), para quem a descentralização não resulta numa repetição das estruturas burocráticas centrais, mas no cumprimento das vontades expressas pela população.

Deixou o Instituto Nacional de Estudos Pedagógicos - Inep -, indo para o Planalto, instado por Darcy Ribeiro, para criar junto com ele a Universidade de Brasília.

RIO DE JANEIRO: O CONSELHEIRO (1962 - 1968)

PLANALTO: O REITOR (1963 - 1964)

OUTRA VEZ NO RIO DE JANEIRO: O TRADUTOR (1967 - 1970)

Assim que foi indicado para o Conselho Federal de Educação, preparou, junto com outros dois conselheiros, D. Cândido Padin e Brochado da Rocha, o parecer sobre Bases 
para a Elaboração de Planos de Educação destinados à aplicação dos Fundos de Ensino, lembrando que "direito à educação representa igualmente uma solução de justiça social", e que pela primeira vez no Brasil a lei manda que a União despenda, de seus recursos para a educação, um terço para o ensino primário, um terço para o ensino médio e um terço para o ensino superior (Teixeira et al., 1962, p. 149).

Ainda em 1962, escreveu o "Bases Preliminares para o Plano de Educação Referente ao Fundo Nacional do Ensino Primário”, reafirmando suas convicções municipalistas e observando que "a educação constitui serviço comum e solidário das três órbitas administrativas do país, competindo à União uma ação supletiva" (Teixeira, 1962, p. 17).

Nesse mesmo texto, com base nos princípios de descentralização e de autonomia presentes no espírito da nova LDB, que levou 13 anos para ser aprovada, reforçou a idéia de que o município é a instância de execução da educação mais próxima da comunidade:

Os sistemas de educação não são, com efeito, algo de abstrato que se possa considerar ligado a toda a população do país, mas conjuntos de escolas vinculados às unidades da população e, em rigor, a cada comunidade local.

Considerá-lo vinculado ao município é o mínimo que temos de admitir ...

A palavra sistema é eminentemente concêntrica, se me permitem a expressão, havendo o sistema nacional, composto de sistemas estaduais e sistemas estaduais compostos de sistemas distritais. E isto é verdade, mesmo que as escolas não estejam sob controle administrativo unificado.

Também, neste sentido, ainda que estaduais e sujeitas ao controle centralizado do estado, as escolas de um determinado município constituem o sistema de escolas estaduais daquele município e, gradativamente, virão a ter o seu controle administrativo próprio, assim que os estados sentirem mais vivamente a necessidade de o fazer, atendendo às condições reais das suas escolas em cada município.

O conceito que estamos procurando definir não é legislativo ou administrativo de sistema, mas o do reconhecimento da escola como instituição presa, de um modo ou de outro, à comunidade a que serve e da qual recebe as influências mais significativas para a sua caracterização real. (Teixeira, 1962, p. 19, grifos nossos)

Falando ainda sobre Plano de Educação e como se daria a assistência financeira de acordo com as prerrogativas do fundo, afirmou que "o auxílio financeiro visaria a expandir o ensino a maior número de alunos e a melhorar a sua qualidade, tendo sempre por base o custo por aluno" (idem, ibidem), portanto, o auxílio financeiro seria um reforço para universalizar o ensino e ajudaria na elevação do nível e qualidade da educação. Ressalta-se aqui a idéia de os recursos financeiros estarem a serviço da democratização e da melhoria de qualidade do ensino.

Em 1963, Anísio Teixeira - como vice-reitor - e Darcy Ribeiro - reitor -, juntos foram os primeiros dirigentes da Universidade de Brasília, depois de três anos projetando e superando dificuldades. Criar "a nossa universidade", como the disse Darcy, era uma 
tarefa grande que Anísio sabia-o e a ela entregou-se de corpo e alma. Como se estivesse realizando uma profecia, disse na época: "Vai ser preciso muita coragem para lutar para que ela não seja violada, para que ela nunca se encasule" (Viana Filho, 1990, p. 166).

Infelizmente a profecia realizou-se. Com a vitória da Revolução de março de 1964, a Universidade de Brasília tornou-se alvo dos militares que assumiram o poder. A universidade foi invadida e Anísio, então reitor, porque Darcy havia assumido a chefia do Gabinete Civil do presidente João Goulart, foi aconselhado pelo diretor da Faculdade de Filosofia a viajar para os Estados Unidos. Aceitou, pois, os convites da Columbia University e da Universidade da Califórnia para dar cursos como visiting scholar (Viana Filho, 1990, p. 167).

Em outubro do mesmo ano, sua saída ficou registrada pelo Conselho Federal de Educação como missão a ser cumprida no "Programa de Intercâmbio Cultural", cooperando com os programas internacionais (Brasil, 1964a, p.21).

Em abril de 1965 Anísio Teixeira foi escolhido conferencista do ano na Califórnia, convite esse feito a grandes educadores internacionais. Nessa conferência, que teve como tema "A democracia e as suas relações criativas na educação: novas fronteiras para a cooperação internacional", pregou novamente o princípio fundamental da democracia, pelo qual tanto lutara no Brasil: a igualdade de oportunidades para todos por meio da educação.

Desde que iniciou seu "amor pelos estudos da educação", frase dita a seu pai há quatro décadas, Anísio Teixeira nunca mais deixaria de lutar pela educação pública. Ao voltar para o Brasil, no final de 1965, ele trazia na alma "desalento e tristeza" e sentindo dificuldade de dar a sua contribuição, como conselheiro, na reconstrução da Universidade de Brasília, que "caminha através da habitual confusão nos objetivos e direções" (Viana Filho, 1990, p.169).

Já de volta às suas funções no Conselho Federal de Educação, esse incansável educador e filósofo escreveu, em 1966, "Sugestões para o Planejamento da Educação nos Territórios", encarregado de relatar o tema do planejamento. Nesse texto argumentou que "apenas poderia apresentar sugestões, pois o planejamento da educação nos territórios só poderá ser feito em face de levantamentos e estudos, que em cada território já tenham sido feitos, ou que se façam para servir de base ao planejamento" (Teixeira, 1966, p. 82). Considerando que os territórios constituíam regiões do país sob a guarda do Governo Federal, e por isso as suas condições econômicas e sociais e as de povoamento não lhes permitiam autonomia política igual à dos estados, Anísio Teixeira propôs sugestões que corroboravam a sua visão filosófica descentralizadora:

Como o governo dos territórios é uma delegação do Poder Central, poderia a sua atuação ali ser mais livre para ensaiar certas concentrações do esforço governamental, evitando os males da divisão e segregação da atuação do governo em cada área do seu programa. (Idem, p. 86)

Procurou assegurar ao longo desse texto que um planejamento da ação pública nos territórios viabilizasse a formação de um centro da comunidade, pela cooperação e integra- 
ção das instituições locais, ou regionais comuns, em diferentes serviços - povoamento, saúde, educação, trabalho, transporte -, com funcionários comuns. Para seu idealizador, esse

...centro embrionário teria uma sala pública com os jornais e um serviço de informação, graças ao qual um habitante poderia informar-se e também apresentar seus problemas de saúde, de trabalho, sobretudo agrícola, e obter respostas e esclarecimento que o agente solicitaria ao Governo Central. Tal centro se desenvolveria, depois dessa célula de comunicação, que era o serviço de correio, telégrafo e telefone, em pequena biblioteca e sua sala de classe, que ficaria a cargo do professor local. (Idem, p. 87)

De todas as suas indicações destaca-se a sua recomendação para que as escolas e demais instituições tenham administração local e autônoma:

A obra da educação, de cultura e de civilização deve ser realizada, tendo em vista que a mesma não se destina a preparar os habitantes do Território, mas para nele ficar, a fim de ali introduzir a cultura mais adiantada em que estão sendo iniciados. Esta sugestão pode parecer até absurda, será viável se o progresso educacional do Território se fizer concomitante com o seu desenvolvimento social e cultural. Isto, acredito, pode vir a dar-se se o desenvolvimento das instituições de cultura locais e regionais se processar adequadamente (biblioteca, museus, etc.) e a direção dos mesmos, como a das instituições escolares, for local e não centralizada. (Teixeira, 1966, p. 88)

No final de 1966, realizou o estudo especial "O problema de formação do magistério", apontando a dualidade da sociedade brasileira e sua conseqüente dualidade educacional, o que se tornaria uma das suas teses mais conhecidas. Nesse estudo Anísio Teixeira denuncia que "o fato dominante nos últimos cinqüenta anos de vida brasileira, com referência à educação, é a expansão e a fusão gradual dos dois sistemas escolares, que serviriam ao país em seu dualismo orgânico de duas sociedades, primeiro de senhores e escravos, depois de senhores e povo" (Teixeira, 1966, p. 5). Os dois sistemas eram separados e independentes, um destinado à formação da elite e outro à formação do povo, ou da classe média emergente. $\bigcirc$ primeiro era um sistema federal com escolas secundárias do tipo acadêmica e escolas superiores, o segundo, um sistema popular estadual com escolas primárias e escolas médias vocacionais. Baseado nessa tese, apontou que a dualidade do sistema escolar também influiu diretamente na formação dos professores. Essa situação só começou a mudar com a expansão educacional, que se deu sob pressão popular, e desenvolveu uma consciência nascente da importância de formar professores para um ensino público, gratuito e universal.

Contudo não nos iludamos. Apesar da expansão, o sistema escolar continua a se destinar a poucos, que por isso mesmo, continuam "privilegiados", embora a escola já não seja a mesma da velha educação humanista, que visava a prepará-los apenas para continuarem a compor a elite social nacional. (Teixeira, 1966, p. II) 
Em janeiro de 1967, encontrou um novo alento quando Octales Marcondes o convidou para trabalhar no Rio de Janeiro, na Editora Nacional, como tradutor. Para ele "a tradução não seria um trabalho, mas um modo de ensinar" (Viana Filho, 1990, p. 185).

Por uma ironia do destino, Anísio Teixeira foi designado, pelo reitor da Universidade do Chile, consultor da Comissão para elaborar o plano de desenvolvimento daquela universidade. Então, com o objetivo de contribuir para o debate a respeito da universidade brasileira leu, em março de 1967, em sessão do Conselho Federal de Educação, as sugestões que elaborou em quatro trabalhos: "A autonomia universitária da América Latina"; "A Universidade do Chile e a sua expansão"; "A expansão da Universidade do Chile e as inovações que sugere seu próprio crescimento"; "A política de admissão que a expansão da Universidade do Chile estaria a recomendar". Ele que havia sido o primeiro vice-reitor e segundo reitor da Universidade de Brasília, cassado e praticamente expulso do Brasil, com esse estudo contribuiu para a expansão da Universidade do Chile e para a formulação dos princípios de sua política de admissão (Teixeira, 1967, p. 9).

Firmando os princípios democráticos, que foram a grande marca de sua vida de luta pela educação, deixou declarado, nesse que foi um dos seus últimos trabalhos como conselheiro, que a missão da universidade é "contribuir para o desenvolvimento econômico da sociedade, o exemplo de sua organização e do seu método de trabalho, autônomos e responsáveis, será a sua grande contribuição à reconstrução democrática dessa mesma sociedade" (idem, p. I2).

Em outubro de 1967 viajou novamente para os Estados Unidos para proferir a palestra "A crise mundial da educação", promovida pela Universidade de Williamsburg, na Virgínia (Brasil, 1967, p. 156).

Um mês antes de deixar o Conselho Federal de Educação, em março do ano seguinte, escreveu um estudo especial sobre a "Interpretação do Artigo I 5 da Lei de Diretrizes e Bases", destacando na lei o espírito dos princípios de autonomia e descentralização:

A autonomia dada pela lei aos estados mais do que tudo procura impedir que os meios desenvolvidos se sintam forçados ao padrão médio de todo o país, quando as suas situações já lhe permitem elevá-lo. A descentralização é o recurso para a elevação de padrões que seria difícil se não impossível se os padrões fossem rigidamente uniformizados pelo poder central, o qual, dadas as condições diferentes das regiões, necessariamente teria de fixá-lo em nível para a média da situação nacional. (Teixeira, 1968, p. 12)

Depois de não ser reconduzido pelo Conselho, continuou "ensinando" como tradutor na Editora Nacional, o que Ihe dava muito prazer especialmente porque tinha oportunidade de traduzir obras clássicas, como por exemplo: A galáxia de Gutemberg, de Marshall MacLuhan; Dois Momentos de pensar, de James Bryant Conant; Cultura e Sociedade, de Raymond Williams; Os Diálogos de Alfred North Whitehead, reconhecidos e publicados por Lucien Price. Essas traduções significavam um "reencontro com Aristóteles e Platão", uma 
velha "sedução pelo pensamento grego" (Viana Filho, 1990, p. 184). Quando resolveu traduzir Tocqueville, manifestou mais uma vez a sua posição filosófica em defesa da democracia: "Ele [Tocqueville] antecipou de certa forma a visão da América de hoje sob a opressão da maioria silenciosa e nos dá o melhor panorama do grande começo da democracia" (idem, p. 192).

Em 1970, aos 70 anos de idade, Anísio foi indicado para concorrer a uma vaga na Academia Brasileira de Letras, e a sua eleição estava sendo esperada com alegria por Fernando de Azevedo que assim lhe escreveu: "Você já pode considerar-se eleito. Ninguém, creio eu, Ihe disputará a cadeira que lhe cabe, por todos os títulos" (idem, p. 204).

Por uma "armadilha do destino" Anísio Teixeira não recebeu o título que seria um reconhecimento público de tudo quanto ele fizera para a educação, vindo a falecer em I I de março do ano seguinte. Após o sepultamento, Péricles Madureira proferiu palavras de ordem para todos aqueles que desejam continuar a sua missão em defesa dos valores democráticos na educação: "Agora temos de aprender a viver sem Anísio" (idem, p. 205).

\section{CONSIDERAÇÕES FINAIS}

aqui chamado ideário pedagógico municipalista, propugnado por Anísio Teixeira, veio sendo construído desde a década de 20 , quando assumiu seu primeiro cargo público na Bahia (1924-1929) e criou, pioneiramente no Brasil, os Conselhos Municipais de Educação. Era uma primeira proposta de descentralização administrativa do ensino estadual.

Na década seguinte, como secretário de educação do Distrito Federal ( 193 I - 1935), pôs em prática aquilo que vinha defendendo na esfera estadual baiana: criou na Secretaria de Educação organismos intermediários que faziam a ponte entre a administração central e o trabalho escolar, evitando separar funcionalmente o trabalho técnico do administrativo. Como presidente e redator da Comissão dos Dez, cumpriu seu compromisso de fazer da experiência educacional do Distrito Federal um referencial para todo o Brasil.

Dez anos depois de "exilado" pelas condições políticas que assombraram o país em 1937, com a reconquista dos princípios democráticos, na Constituição de 1946, voltou à Bahia para dar continuidade, como secretário de educação e saúde (| 947- | 95 I), ao seu ideário pedagógico municipalista, elaborando um anteprojeto de lei orgânica de educação e cultura, com vistas à eficácia da descentralização administrativa.

Trinta anos depois de assumir seu primeiro cargo público, já como diretor do Inep, conclamou os que vinham lutando pela democratização do país a também se envolverem na causa da descentralização e autonomia dos municípios, objetivando uma escola integrada à comunidade local.

Nos anos 60, a última década de sua existência, continuou ensinando sobre educação e democracia nas obras que escreveu como conselheiro, na sua atuação como vice-reitor e depois reitor da Universidade de Brasília, e finalmente, como tradutor na Editora Nacional. 
O propugnado ideário pedagógico municipalista emergiu dos valores democráticos que Anísio Teixeira consagrou para a educação.

Consagrado pelos intelectuais de sua época, deixou publicada em uma série de livros e artigos a sua filosofia de educação para uma sociedade democrática. Recebeu vários epítetos que fazem referência a sua capacidade intelectual: "vulcão de idéias", para Delgado de Carvalho; "a inteligência", para Fernando de Azevedo; "o pensador", para Lourenço Filho. Darcy Ribeiro reconhecia nele um "pensador e homem de ação", do mesmo modo como Afrânio Coutinho dizia que Anísio estava sempre "pensando com a cabeça e as mãos". A capacidade intelectual e a competência administrativa resultaram no seu pioneirismo na educação, o que fez Gilberto Freire chamá-lo "o grande renovador da cultura brasileira" (Abreu, 1960).

O ideário pedagógico municipalista de Anísio Teixeira, mais do que nunca, precisa ser lembrado, posto em prática e inovado por aqueles que, como ele, acreditam que "a municipalização de ensino só é defensável se puder contribuir para a melhoria do ensino" público brasileiro. Assim ele profetizou um pouco antes de morrer: "Somos algo inacabado, a buscar sempre, e se tudo encontrássemos não seríamos homens..." (Viana Filho, 1990, p. 180).

\section{REFERÊNCIAS BIBLIOGRÁFICAS}

ABREU, J. Anísio Teixeira e a educação na Bahia. In: ABREU, J. et al. Anísio Teixeira: pensamento e ação. Rio de Janeiro: Civilização Brasileira, 1960.

AZANHA, J. M. P. Educação: temas polêmicos. São Paulo: Martins Fontes, 1995. Uma idéia sobre a municipalização do ensino.

AZEVEDO, F. de A Cultura brasileira. 6.ed. Rio de Janeiro: UFRJ; Brasília: UnB, 1996.

BRASIL. Ministério da Educação e Cultura. C. F. E. A Crise mundial da educação. Documenta, n. 74, out. 1967.

Parecer n. 146/64, aprov. em 5-6-1964. Documenta, n. 27, jun. 1964.

Viagem Cultural do Conselheiro Anísio Teixeira. Documenta, n. 30, out. 1964a.

BROOKE, N. Os condicionantes da descentralização da educação: um roteiro de estudo. Cadernos de Pesquisa, n. 70, p.3-95, ago. 1989.

DEWEY, J. Democracia e educação: breve tratado de filosofia de educação. 2.ed. São Paulo: Cia. Nacional, 1952. A Concepção democrática da educação.

FAUSTO, B. História do Brasil. 5.ed. São Paulo: EDUSP; FDE, 1997.

HAIDAR, M. L. M., TANURI, L. M. A Educação básica no Brasil: dos primóridos até a primeira 
Lei de Diretrizes e Bases. In: MENESES et al. Estrutura e funcionamento da educação básica: leituras. São Paulo: Pioneira, 1998.

HOLANDA, S. B. Índios e mamelucos na expansão paulista. Anais do Museu Paulista, São Paulo, v. 3, p. 176-290, 1949.

LEMME, P. Memórias 2: vida de família, formação profissional, opção política. São Paulo: Cortez; [Brasília, DF]: INEP, 1988. v. 2.

SANTOS, H. O. Municipalização do ensino em São Paulo: vicissitudes do ideário de Anísio Teixeira. São Paulo, 2000. Tese (dout.) FEUSP.

SILVEIRA, J. Alguns aspectos da reforma Anísio Teixeira no Rio de Janeiro. In: ABREU, J. et al. Anísio Teixeira: pensamento e ação, 1960.

TAVARES, O. Prioridade número um para a educação: entrevista de Anísio Teixeira ao Diário de Notícias da Bahia, Rio de Janeiro: Ministério da Educação e Saúde, 1952. (Serviço de Documentação)

TEIXEIRA, A. S. Aspectos da reconstrução da universidade latino-americana: estudo especial. Documenta, n. 67, fev./mar. 1967.

Bases preliminares para o Plano de Educação referente ao Fundo Nacional do Ensino Primário. Documenta, n.4, jun. 1962.

A Crise educacional brasileira. Revista Brasileira de Estudos Pedagógicos, v. 19 , n. 50, p. 20-43, abr./jun. 1953.

- Educação para a democracia: introdução à administração educacional. Rio de Janeiro: José Olympio, 1936.

TEIXEIRA, A. S. Educação para a Democracia: introdução à administração educacional. Rio de Janeiro: José Olympio, 1936. A Educação e a Constituição Federal.

. Educação não é privilégio. 4. ed. São Paulo: Nacional, 1977.

Ensino cabe à sociedade. Revista Brasileira de Estudos Pedagógicos. v. 31 , n.74, abr.jun. 1959.

Ensino no Estado da Bahia 1924-1928. In: ABREU, J. Anísio Teixeira e a educação na Bahia. Rio de Janeiro: Civilização Brasileira, 1960.

Falando francamente. Revista Brasileira de Estudos Pedagógicos. n. 72, out./ dez. 1958.

Interpretação do Artigo I 5 da Lei de Diretrizes e Bases. Documenta, n. 8I , fev. 1968.

A Municipalização do ensino primário. Revista Brasileira de Estudos Pedagógicos. v. 27, n. 66, abr./jun. 1957. 
O Problema da formação do magistério. Documenta, n. 62, nov. 1966.

O Processo democrático de educação. Revista Brasileira de Estudos Pedagógicos. v. 25, n. 62, abr.jun. 1956

Sobre o problema de como financiar a educação do povo brasileiro. Revista Brasileira de Estudos Pedagógicos. n. 52, out./dez. 1954.

Sugestões para o planejamento da educação nos Territórios. Documenta, n. 58, ago./set. 1966.

TEIXEIRA, A. S. et al. Bases para a elaboração de Planos de Educação destinados a aplicação dos Fundos de Ensino. Documenta, n. I, mar. 1962.

VARGAS, G. Discurso pronunciado a 13 de dezembro de 1931, no Palácio Tiradentes durante a Sessão Solene de Instalação da IV Conferência Nacional de Educação. Jornal do Comércio. Rio de Janeiro, D.F, I93I.

VIANA FILHO, L. Anísio Teixeira: a polêmica da educação. Rio de Janeiro: Nova Fronteira, 1990. 